\title{
Expressão do potencial de rendimento de cultivares de soja ${ }^{(1)}$
}

\author{
Hugo Motta Navarro Júnior ${ }^{(2)}$ e José Antonio Costa ${ }^{(3)}$
}

\begin{abstract}
Resumo - A soja possui alto potencial de rendimento de grãos, mas em virtude da interação genótipo vs. ambiente esse potencial não é verificado em sua totalidade. Utilizando-se seis genótipos de soja de diferentes ciclos, objetivou-se estudar a expressão do potencial de rendimento de grãos e quantificá-lo durante a ontogenia. O experimento foi conduzido no ano agrícola 1996/97 na Estação Experimental Agronômica da Universidade Federal do Rio Grande do Sul, Eldorado do Sul, RS. As avaliações foram realizadas em plantas individuais e se estenderam desde o estádio de floração até o de maturação. Os resultados obtidos indicam que alto potencial de rendimento não necessariamente identifica uma planta eficiente na retenção das estruturas reprodutivas. Os potenciais de rendimento estimados na floração e no início do enchimento de grãos não se mantêm até a maturação. Genótipos com alto potencial de rendimento de grãos em R8 não apresentam os maiores potenciais de rendimento de grãos em R2 e em R5, porém, são os que apresentam as menores diferenças entre o potencial estimado em R5 e o estimado em R2.
\end{abstract}

Termos para indexação: Glycine max, grãos, ontogenia, componentes de rendimento.

\section{Yield potential expression of soybean genotypes}

\begin{abstract}
Soybean has high yield potential, which is not totally expressed due to genotype vs. environment interaction. Six soybean genotypes of different maturity groups were used with the objective of studying their yield potential expression and quantifying it during ontogeny. The experiment was conducted during the 1996/97 growing season in the Agronomic Experimental Station of the Universidade Federal do Rio Grande do Sul, Eldorado do Sul, RS, Brazil. Plants were evaluated individually from flowering until maturity. Results obtained indicate that high yield potential does not necessarily mean an efficient plant in reproductive structure retention. Yield potential estimated in the flowering and beginning of grain filling stages are not maintained until maturity. Genotypes with high yield potential in the R8 stage do not present the highest yield potential in the R2 and R5 stages, but the lowest differences between potential estimated in the R5 stage and the one estimated in the R2 stage.
\end{abstract}

Index terms: Glycine max, grain, ontogeny, yield components.

\section{Introdução}

Nos últimos anos, têm sido comuns afirmativas de que a produtividade das culturas está começando a atingir o patamar máximo e que aumentos nos rendimentos de grãos logo cessarão.

(1) Aceito para publicação em 24 de maio de 2001 .

Extraído da Dissertação de Mestrado apresentada pelo primei- ro autor à Universidade Federal do Rio Grande do Sul (UFRGS), Porto Alegre, RS.

(2) Rua Felipe Camarão, 72/22, Bairro Bom Fim, CEP 90035140 Porto Alegre, RS. E-mail: navarrojr@hotmail.com

(3)UFRGS, Dep. de Plantas de Lavoura, Av. Bento Gonçalves, 7712, Bairro Agronomia, CEP 91509-900 Porto Alegre, RS. E-mail: jamc@vortex.ufrgs.br
Apesar de a soja possuir elevado potencial de rendimento de grãos, parte desse pontencial é perdido em razão do aborto e da abscisão das estruturas reprodutivas (flores, legumes e grãos), reflexo da interação com o ambiente e da competição entre os órgãos por assimilados durante o ciclo de desenvolvimento. Segundo Dybing (1994), o fenômeno da grande produção de flores pela soja e sua capacidade de produzi-las após iniciado o enchimento de grãos definem a existência de elevado potencial reprodutivo, porém isso não se materializa e, conseqüentemente, $o$ rendimento final de grãos é afetado.

O potencial de rendimento de grãos pode ser definido como a produção de uma cultivar em ambiente ao qual está adaptada, sem limitações edafoclimáticas e nutricionais, livre da ação de pra- 
gas e de doenças, e com os demais estresses efetivamente controlados (Evans, 1993). Representa a máxima produção do genótipo quando os fatores bióticos e abióticos que impedem a plena expressão de seu potencial genético são minimizados.

No estudo dos fatores que regulam a produção de grãos em soja, muita ênfase tem sido dada para o período de enchimento de grãos, quando o tamanho do grão é determinado (Dybing, 1994). Por sua vez, menos entendidos são os fatores que atuam durante a floração, quando o número potencial de legumes por planta e de grãos por legume são, em grande parte, determinados (McBlain \& Hume, 1981).

O rendimento de grãos em soja pode ser determinado, basicamente, pelo número de flores que cada planta pode produzir e pela quantidade destas que se desenvolvem até legumes férteis maduros (Jiang \& Egli, 1993). Contudo, muitas flores de soja caem e, conseqüentemente, não contribuem para a produção de grãos. As estruturas reprodutivas que surgem na posição proximal de inserção no nó são as que se desenvolvem primeiro e estabelecem mais cedo o tamanho de demanda superior em relação às estruturas que surgem na posição distal do racemo, que são mais propensas à abscisão (Spollen et al., 1986; Wiebold, 1990).

O número de legumes por planta e de grãos por legume são os dois componentes mais importantes do rendimento de grãos da soja, pois a redução do número de grãos é apenas parcialmente compensada pelo incremento no tamanho dos mesmos (Herbert \& Litchfield, 1982). O número de grãos por legume é fortemente influenciado pelo fato de que a maioria das cultivares modernas são selecionadas para formar três óvulos por legume. Mesmo que os legumes formados mais tarde, freqüentemente, tenham número menor de óvulos, o aborto destes e de grãos também pode ocorrer (McBlain \& Hume, 1981).

O objetivo deste trabalho foi estudar a expressão do potencial de rendimento de grãos e quantificá-lo durante a ontogenia de seis genótipos de soja.

\section{Material e Métodos}

O experimento foi realizado no ano agrícola 1996/97, na Estação Experimental Agronômica da Universidade Federal do Rio Grande do Sul (EEA/UFRGS), localizada no Município de Eldorado do Sul, RS, em solo classificado como Podzólico Vermelho-Escuro distrófico. Foi empregado o delineamento experimental de blocos completamente casualizados, com quatro repetições. Os tratamentos constituíram-se de seis cultivares de soja de hábito de crescimento determinado, sendo duas de ciclo precoce (FT-2003 e OCEPAR 14), duas de ciclo médio (BR 16 e RS 7-Jacuí) e duas de ciclo semitardio (RS 9-Itaúba e CEP 20-Guajuvira), indicadas para cultivo no Rio Grande do Sul.

As parcelas foram locadas em área sob o sistema de semeadura convencional, preparada com uma aração e três gradagens. Com base na análise do solo, foram aplicados a lanço, em toda a área experimental, $200 \mathrm{~kg} \mathrm{ha}^{-1} \mathrm{de}$ adubo da fórmula 5-20-20 e $33 \mathrm{~kg} \mathrm{ha}^{-1}$ de superfosfato triplo. Os fertilizantes foram incorporados ao solo.

A semeadura foi realizada em 22/11/1996, manualmente, em quatro linhas, espaçadas de $0,4 \mathrm{~m}$, com $5 \mathrm{~m}$ de comprimento, de modo a garantir a população de 40 plantas $\mathrm{m}^{-2}$. Aos 37 dias após a emergência (6/1/1997), quando as plantas encontravam-se com seis a sete folhas desenvolvidas, foram marcadas em cada parcela cinco plantas na linha de cultivo, que apresentassem aproximadamente o mesmo porte e eqüidistância de área disponível para seu desenvolvimento. Foram realizadas observações sistemáticas nessas cinco plantas durante o ciclo de desenvolvimento, quanto ao crescimento do caule e dos ramos e da localização, do tipo e da quantidade de estruturas reprodutivas, em cada estádio avaliado.

Para estimar o potencial de rendimento de grãos na floração (R2) e no início do enchimento de grãos (R5), determinaram-se, a partir dos dados obtidos na maturação (R8), as porcentagens de legumes contendo um, dois e três grãos e o peso médio de 100 grãos, em cada cultivar. Os dados obtidos foram aplicados aos valores de número de estruturas reprodutivas determinados em R2 e R5, sendo os dados de peso final de grãos das cinco plantas convertidos a quilogramas por hectare.

Durante o ciclo de cultivo, a umidade do solo foi mantida na capacidade de campo por meio de irrigação por aspersão. O controle de plantas daninhas e de insetos-praga foi feito segundo as recomendações técnicas para a cultura da soja, de modo a não interferirem nos resultados (Reunião..., 1995).

\section{Resultados e Discussão}

As cultivares apresentaram diferenças significativas em relação ao número de estruturas reprodutivas presentes por nó fértil da planta (Tabela 1). Apesar de as cultivares RS 7-Jacuí e BR 16 não terem apre- 
sentado o maior número de legumes por nó fértil em $\mathrm{R} 8$, em R2 foram as que produziram maior número de flores por nó fértil. Esta alta produção de flores em R2, provavelmente, estabeleceu elevada competição no racemo, ocasionando baixa porcentagem de fixação de legumes, pelo aumento da competição entre as estruturas presentes.

A competição entre estruturas reprodutivas no racemo de soja é, possivelmente, o início do processo de abscisão da estrutura sem capacidade ou força para competir pelos fotoassimilados disponíveis. Alguns estudos têm indicado que o controle do aborto de estruturas reprodutivas atua na região do nó (Spollen et al., 1986; Wiebold, 1990), sugerindo que o suprimento de assimilados é fator importante neste processo (Wiebold \& Panciera, 1990).

Apesar de as cultivares apresentarem comportamentos distintos com relação ao número de flores produzidas por planta, essas diferenças não foram verificadas no início do enchimento de grãos (R5) e na maturação (R8), pois elas não diferiram entre si quanto ao número de legumes produzidos e fixados por planta (Tabela 2). As cultivares com maior produção de flores não apresentaram maior número de legumes nos estádios posteriores porque diferiram quanto à porcentagem de fixação de flores e, conseqüentemente, aquelas com maior produção destas estruturas tiveram menores condições de manter todas até os estádios posteriores.

As cultivares FT-2003 e RS 9-Itaúba foram significativamente superiores às demais com relação à

Tabela 1. Número de estruturas reprodutivas (flores e legumes) por nó fértil da planta, nos estádios fenológicos de floração (R2), início do enchimento de grãos (R5) e de maturação (R8), de seis cultivares de soja. EEA/UFRGS, Eldorado do Sul, RS, 1996/97(1).

\begin{tabular}{lccc}
\hline Cultivar & \multicolumn{3}{c}{$\begin{array}{c}\text { Número de estruturas reprodutivas } \\
\text { (flores e legumes) }\end{array}$} \\
\cline { 2 - 4 } & $\mathrm{R} 2$ & $\mathrm{R} 5$ & $\mathrm{R} 8$ \\
\hline FT-2003 & $6,7 \mathrm{~b}$ & $3,5 \mathrm{a}$ & $2,2 \mathrm{bcd}$ \\
OCEPAR 14 & $6,2 \mathrm{~b}$ & $2,6 \mathrm{~b}$ & $1,8 \mathrm{~d}$ \\
BR 16 & $7,2 \mathrm{ab}$ & $2,7 \mathrm{~b}$ & $2,0 \mathrm{~cd}$ \\
RS 7-Jacuí & $8,3 \mathrm{a}$ & $3,8 \mathrm{a}$ & $2,4 \mathrm{bc}$ \\
RS 9-Itaúba & $6,1 \mathrm{~b}$ & $2,5 \mathrm{~b}$ & $2,5 \mathrm{~b}$ \\
CEP 20-Guajuvira & $6,4 \mathrm{~b}$ & $3,5 \mathrm{a}$ & $3,2 \mathrm{a}$ \\
\hline CV (\%) & 12,0 & 9,7 & 12,8 \\
\hline (1)Médias seguidas da mesma letra na coluna não diferem entre si pelo teste \\
de Duncan a 5\% de probabilidade.
\end{tabular}

produção de grãos por planta, com exceção de RS 7-Jacuí. No entanto, elas não foram, exatamente, as que apresentaram maior potencial de rendimento na floração (R2), uma vez que não apresentaram maior número de flores neste estádio. Portanto, ao contrário da maior produção de flores, a porcentagem destas que foram efetivamente fixadas em legumes maduros presentes em R8 é que determinou a maior produção final de grãos por planta dos genótipos FT-2003 e RS 9-Itaúba (Tabela 2). A importância da fixação de flores para o rendimento de grãos em soja foi constatada no trabalho de Sharma et al. (1990), em que o rendimento de grãos de soja foi elevado por meio da seleção de genótipos com baixo nível de abscisão de flores.

A baixa produção de flores da cultivar CEP 20-Guajuvira, se deve, provavelmente, à produção tardia de ramos, pois na fase de floração não apresentava grande quantidade de nós para o surgimento de estruturas reprodutivas, que aumentaram a partir desta fase. Por sua vez, apresentou alta porcentagem de fixação de legumes, tendo até mesmo ultrapassado o número de flores presentes em R2 (Tabela 2). O longo período de floração, que ocorreu concomitantemente com a produção e a fixação de legumes, aliada à alta quantidade de estruturas reprodutivas presentes por nó fértil a partir de R5 (Tabela 1), colaborou para o estabelecimento de competição entre estruturas reprodutivas, causando menor produção de grãos por planta neste genótipo (Tabela 2).

Tabela 2. Produção e fixação de flores, de legumes e de grãos na planta de seis cultivares de soja. EEA/UFRGS, Eldorado do Sul, RS, 1996/97(1).

\begin{tabular}{lcccc}
\hline Cultivar & $\begin{array}{c}\text { Flores } \\
\text { produzidas } \\
(\mathrm{R} 2)\end{array}$ & $\begin{array}{c}\text { Legumes } \\
\text { produzidos } \\
\text { (R5) }\end{array}$ & $\begin{array}{c}\text { Legumes Produção } \\
\text { fixados } \\
\text { (R8) }\end{array}$ & $\begin{array}{c}\text { de grãos } \\
\text { (g/planta) }\end{array}$ \\
\hline FT-2003 & $120 \mathrm{ab}$ & $86 \mathrm{a}$ & $54 \mathrm{a}$ & $18,02 \mathrm{a}$ \\
OCEPAR 14 & $144 \mathrm{ab}$ & $58 \mathrm{a}$ & $40 \mathrm{a}$ & $11,00 \mathrm{~b}$ \\
BR 16 & $133 \mathrm{ab}$ & $64 \mathrm{a}$ & $41 \mathrm{a}$ & $13,60 \mathrm{~b}$ \\
RS 7-Jacuí & $156 \mathrm{a}$ & $75 \mathrm{a}$ & $43 \mathrm{a}$ & $14,82 \mathrm{ab}$ \\
RS 9-Itaúba & $101 \mathrm{~b}$ & $59 \mathrm{a}$ & $57 \mathrm{a}$ & $17,82 \mathrm{a}$ \\
CEP 20-Guajuvira & $58 \mathrm{c}$ & $67 \mathrm{a}$ & $62 \mathrm{a}$ & $13,67 \mathrm{~b}$ \\
\hline CV (\%) & 22,2 & 23,6 & 23,0 & 16,0 \\
\hline (1)Médias seguidas da mesma letra na coluna não diferem entre si pelo teste \\
de Duncan a 5\% de probabilidade; R2: floração; R5: início do enchimento \\
de grãos; R8: maturação.
\end{tabular}

Pesq. agropec. bras., Brasília, v. 37, n. 3, p. 275-279, mar. 2002 
O número de grãos por legume é outro componente importante do rendimento de grãos em soja, tanto que as cultivares modernas são selecionadas para formar três grãos por legume. Quando se compara os dados de número de legumes contendo um, dois e três grãos (Tabela 3) com os dados de produção de grãos por planta (Tabela 2), observa-se que, no caso da cultivar FT-2003, a produção de grãos por planta está relacionada ao elevado número de legumes contendo três grãos. Já a cultivar RS 9-Itaúba, também superior com relação à produção de grãos por planta (Tabela 2), apresentou baixo número de legumes contendo três grãos, os quais foram compensados pelo alto número de legumes contendo dois grãos (Tabela 3).

Em R5, a planta necessita de energia para manter os legumes, para suprir a demanda de novas estruturas reprodutivas que vão surgindo (flores) e ainda encher os grãos. Esta competição por assimilados pode levar a uma perda de potencial, originando legumes com um e com dois grãos. A menor produção de flores em R2 permitirá, por meio da diminuição da demanda em R5, que se formem legumes maiores, com maior número e peso de grãos. A perda do número de grãos pela produção de legumes com um ou com dois grãos (Tabela 3) ocasionou, nos genótipos estudados, uma perda de potencial em relação à produção total da planta, assumindo que todos os legumes fixados pela planta poderiam ter produzido três grãos. Assim, acredita-se que o menor número de flores pode tornar possível o aumento da produção de legumes com três grãos, beneficiando a produção final da planta.

Tabela 3. Número de legumes por planta contendo um, dois e três grãos, na maturação (R8) de seis cultivares de soja. EEA/UFRGS, Eldorado do Sul, RS, 1996/97(1).

\begin{tabular}{lccc}
\hline \multirow{2}{*}{ Cultivar } & \multicolumn{3}{c}{ Número de legumes por planta } \\
\cline { 2 - 4 } & Um grão & Dois grãos & Três grãos \\
\hline FT-2003 & $9 \mathrm{a}$ & $23 \mathrm{~b}$ & $21 \mathrm{a}$ \\
OCEPAR 14 & $10 \mathrm{a}$ & $22 \mathrm{~b}$ & $9 \mathrm{c}$ \\
BR 16 & $10 \mathrm{a}$ & $23 \mathrm{~b}$ & $8 \mathrm{c}$ \\
RS 7-Jacuí & $6 \mathrm{~b}$ & $23 \mathrm{~b}$ & $14 \mathrm{~b}$ \\
RS 9-Itaúba & $11 \mathrm{a}$ & $38 \mathrm{a}$ & $8 \mathrm{c}$ \\
CEP 20-Guajuvira & $12 \mathrm{a}$ & $39 \mathrm{a}$ & $11 \mathrm{bc}$ \\
\hline CV (\%) & 23,7 & 25,0 & 30,5 \\
\hline (1) Médias seguidas da mesma letra na coluna não diferem entre si pelo teste \\
de Duncan a 5\% de probabilidade.
\end{tabular}

A estimativa do potencial de rendimento de grãos em R8 (Tabela 4) foi obtida por meio da extrapolação dos valores de rendimento de grãos determinados na área amostral. Para os estádios R2 e R5, o potencial de rendimento foi estimado com base no número de estruturas reprodutivas presentes nos mesmos.

Durante a floração foi estimado o máximo potencial de rendimento de grãos das cultivares, sendo a cultivar RS 7-Jacuí a que atingiu o maior valor neste estádio, superando $20.000 \mathrm{~kg} \mathrm{ha}^{-1}$ de grãos. As demais cultivares atingiram, aproximadamente, $67 \%$ desse potencial (média de $13.760 \mathrm{~kg} \mathrm{ha}^{-1}$ de grãos), com exceção da CEP 20-Guajuvira, que atingiu $24 \%$.

Em R5, o potencial estimado foi superior a $10.000 \mathrm{~kg} \mathrm{ha}^{-1}$ de grãos em relação às cultivares FT-2003 e RS 7-Jacuí, diferindo significativamente das demais cultivares com potencial médio estimado de $6.950 \mathrm{~kg} \mathrm{ha}^{-1}$ de grãos. Nesse estádio fenológico, as cultivares atingiram, em média, $60 \%$ do potencial de rendimento de grãos estimado em R2, com exceção da cultivar CEP 20-Guajuvira, que obteve valores superiores ao seu potencial estimado em R2.

A estimativa do potencial de rendimento de grãos em soja baseia-se na produção de flores e de legumes por planta, de grãos por legume e peso de grãos. Assim, as diferenças encontradas entre os genótipos estudados quanto ao potencial de rendimento de grãos devem-se às diferenças na produção (R2) e na fixação (R5) de flores dos mesmos (Tabela 2).

Tabela 4. Estimativa do potencial de rendimento de grãos nos estádios fenológicos da floração (R2) e início do enchimento de grãos (R5) e rendimento final de grãos na maturação (R8) de seis cultivares de soja. EEA/UFRGS, Eldorado do Sul, RS, 1996/97(1).

\begin{tabular}{|c|c|c|c|c|c|c|}
\hline \multirow[t]{3}{*}{ Cultivar } & \multicolumn{6}{|c|}{ Estimativa do potencial de rendimento de grãos } \\
\hline & \multicolumn{2}{|c|}{$\mathrm{R} 2$} & \multicolumn{2}{|c|}{ R5 } & \multicolumn{2}{|c|}{ R8 } \\
\hline & $\mathrm{kg} \mathrm{ha}^{-1}$ & $\%$ & $\mathrm{~kg} \mathrm{ha}^{-1}$ & $\%$ & $\mathrm{~kg} \mathrm{ha}^{-1}$ & $\%$ \\
\hline FT-2003 & $14.638 b$ & 100 & $11.620 \mathrm{a}$ & 79 & $6.436 \mathrm{a}$ & 45 \\
\hline OCEPAR & $15.032 b$ & 100 & $7.152 b$ & 48 & $3.929 b$ & 28 \\
\hline BR 16 & $15.225 \mathrm{~b}$ & 100 & $7.917 \mathrm{~b}$ & 52 & $4.857 \mathrm{~b}$ & 31 \\
\hline RS 7-Jacuí & $20.391 \mathrm{a}$ & 100 & $10.782 \mathrm{a}$ & 53 & $5.293 \mathrm{ab}$ & 27 \\
\hline RS 9-Itaúba & $10.147 \mathrm{~b}$ & 100 & $6.836 \mathrm{~b}$ & 67 & $6.364 a$ & 62 \\
\hline CEP & $4.946 \mathrm{c}$ & 100 & $5.893 b$ & 119 & $4.882 \mathrm{~b}$ & 105 \\
\hline CV (\%) & 22,0 & & 19,2 & & 16,0 & \\
\hline
\end{tabular}


Trabalhos de Sharma et al. (1990) demonstram que a seleção para um menor número de flores por nó é mais fácil que tentar diminuir a porcentagem de queda das mesmas, em razão da herdabilidade da característica. Nesse sentido, um número adequado de flores por racemo poderia ser mais conveniente para a obtenção de altos rendimentos de grãos do que alta produção de flores, as quais, na maioria, são abortadas, causando desperdício de energia na planta e, conseqüentemente, reduzindo o potencial para obtenção de rendimentos elevados de grãos.

\section{Conclusões}

1. A produção moderada de flores e de estruturas reprodutivas por nó fértil, aliada à produção de legumes com dois ou com três grãos, é responsável pela expressão do alto potencial de rendimento de grãos nos genótipos FT-2003 e RS 9-Itaúba.

2. Genótipos com alto potencial de rendimento de grãos em R8 não apresentam os maiores potenciais de rendimento de grãos em R2 e em R5, porém, são os que apresentam as menores diferenças entre o potencial estimado em R5 e o estimado em R2.

3. A característica de alta produção de flores não parece ser adequada para a seleção de plantas com maior potencial de produção de grãos, uma vez que não se traduz em maior produção final de grãos por planta.

\section{Referências}

DYBING, C. D. Soybean flower production as related to plant growth and seed yield. Crop Science, Madison, v. 34, n. 2, p. 489-497, Mar./Apr. 1994.
EVANS, L. T. Crop evolution, adaptation and yield. Cambridge, Inglaterra: Cambridge University Press, 1993. $500 \mathrm{p}$.

HERBERT, S. J.; LITCHFIELD, G. V. Partitioning soybean seed yield components. Crop Science, Madison, v. 22 , n. 5, p. 1074-1079, Sept./Oct. 1982.

JIANG, H.; EGLI, D. B. Shade induced changes in flower and pod number and flower and fruit abscission in soybean. Agronomy Journal, Madison, v. 85, n. 2, p. 221-225, Mar./Apr. 1993.

McBLAIN, B. A.; HUME, D. J. Reproductive abortion, yield components and nitrogen content in three early soybean cultivars. Canadian Journal of Plant Science, Ottawa, v. 61, n. 3, p. 499-505, July 1981.

REUNIÃO DE PESQUISA DE SOJA DA REGIÃO SUL, 23., 1995, Porto Alegre. Recomendações técnicas para a cultura da soja no Rio Grande do Sul e Santa Catarina: 1995/96. Porto Alegre: UFRGS, 1995. 80 p.

SHARMA, K. P.; DYBING, C. D.; LAY, C. Soybean flower abortion: genetics and impact of selection on seed yield. Crop Science, Madison, v. 30, n. 5, p. 1017-1022, Sept./Oct. 1990.

SPOLLEN, W. G.; WIEBOLD, W. J.; GLENN, D. S. Intraraceme competition in field-grown soybean. Agronomy Journal, Madison, v. 78, n. 2, p. 280-283, Mar./Apr. 1986.

WIEBOLD, W. J. Rescue of soybean flowers destined to abscise. Agronomy Journal, Madison, v. 82, n. 1, p. 8588, Jan./Feb. 1990.

WIEBOLD, W. J.; PANCIERA, M. T. Vasculature of soybean racemes with altered intraraceme competition. Crop Science, Madison, v. 30, n. 5, p. 1089-1093, Sept./ Oct. 1990. 